Original Research Article

\title{
Prescription analysis of hypolipidaemic agents in the department of cardiology in a tertiary care hospital
}

\author{
Manju Gari, Megha Bansal*
}

Department of Pharmacology and therapeutics, Rajendra Institute of Medical Sciences, Ranchi, Jharkhand, India

Received: 19 September 2019 Accepted: 17 October 2019

*Correspondence to:

Dr. Megha Bansal, Email: megha258036@ gmail.com

Copyright: (C) the author(s), publisher and licensee Medip Academy. This is an openaccess article distributed under the terms of the Creative Commons Attribution NonCommercial License, which permits unrestricted noncommercial use, distribution, and reproduction in any medium, provided the original work is properly cited.

\begin{abstract}
Background: The objective of the present study was to evaluate the prescribing pattern of hypolipidaemic drugs in the outpatient department of cardiology in a tertiary care hospital.

Methods: A cross-sectional study was conducted in the department of cardiology for the period of 3 months. A total of 526 prescriptions were analyzed for variants such as the disease patterns, the type of hypolipidaemic drugs which are prescribed for those diseases, the prescribing daily dose of the hypolipidaemic drugs and the prescribing daily dose/daily defined dose ratio of the drugs.

Results: On evaluation of the prescriptions, it was conferred that both the patients of normal lipid profile (34.77\%) and abnormal lipid profile $(65.18 \%$ ) were prescribed hypolipidaemic drug. Diabetes with hypertension (35.74\%) was the most common disease for which hypolipidaemic drugs were prescribed. Atorvastatin (30.98\%) was the most common drug which was prescribed as monotherapy, whereas atorvastatin with aspirin and clopidogrel (17.49\%) was the most common drug prescribed in combination.

Conclusions: Use of statin has become very prevalent with increasing trends of use in both normal and abnormal lipid profile patients, suggesting consideration of rational use of statins to follow good prescribing pattern so that morbidity and mortality can be prevented.
\end{abstract}

Keywords: Statins, Hypolipidaemic agents, Prescribing pattern

\section{INTRODUCTION}

Cardiovascular disease (CVD) is the leading cause of death among adults worldwide, and hyperlipidemia increases the risk by twice for developing CVD as compared to those with normal total cholesterol levels. ${ }^{1}$ Lipids play an important role but not an exclusive role in the development and progression of cardiovascular disease. Hyperlipidemia is a potent risk factor for atherosclerosis and atherosclerosis induced conditions like coronary heart disease (CHD), ischemic cerebrovascular disease and peripheral vascular disease and is present in a considerable proportion of population. According to 2013 data from the National Health and Nutrition Examination Survey, between $11.7 \%$ of adults aged 20-39 and $41.2 \%$ of adults aged 40-64 had elevated low-density lipoprotein cholesterol (LDL-C) levels, but only $10.6 \%$ of adults aged $20-39$ and $47.7 \%$ of adults age
40-64 with hyperlipidemia were on treatment. ${ }^{2}$ The atherosclerotic lesion may occlude the vessel wall causing many complications, but the rupture of unocclusive lesions is more dangerous causing sudden death and Acute Coronary Syndrome. The newly released American Heart Association/American College of Cardiology (ACC) 2018 guidelines for treatment of blood cholesterol for the prevention of CVD recommend statin therapy for all adults with prevalent CVD, LDL-C $\geq 190$ $\mathrm{mg} / \mathrm{dl}$, diabetes, or 10-year risk of atherosclerotic CVD $\geq 7.5 \%$, as assessed by the new pooled cohort equations. ${ }^{3}$ Due to obesity and high glycaemic load with insulin resistance, hypertriglyceridaemia is becoming more prevalent in Indian population and it is for this reason that antiatherosclerotic therapy (lipid lowering therapy) should necessarily be added in the treatment of patients with $\mathrm{CHD}$ or at high risk of CHD. 


\section{METHODS}

This cross-sectional study was conducted in the outpatient Department of Cardiology in a tertiary care teaching hospital of Jharkhand. Institutional ethics committee has been acknowledged. This study was conducted for a period of 3 months (December 2018 to February 2019). The prescriptions of patients who attended the outpatients department were noted down after obtaining verbal consent from them. Patients of both genders and who were in age 21 years and above, who were prescribed with at least one hypolipidaemic drug were included in the study. Patients who were below the age of 21 years and who did not receive a single hypolipidaemic drug were excluded from the study. Based on the inclusion and exclusion criteria, a total of 526 patients prescriptions were selected for the study. The prescriptions given during the follow up visits were generally considered as same prescriptions. However, in case another hypolipidaemic drug was added or if there was a change in any hypolipidaemic drug; then they were regarded as different prescriptions. The selected prescriptions were analyzed for variants such as the disease patterns, the type of hypolipidaemic drugs which are prescribed for those diseases, the prescribing daily dose (PDD) of the hypolipidaemic drugs and the PDD/ daily defined dose (DDD) ratio of the drugs. The Anatomical Therapeutic Chemical (ATC) classification and the DDD of the hypolipidaemic drugs were found to be, as indicated by World Health Organization. The ATC codes and the daily defined doses for some fixed dose combinations of hypolipidaemic drugs were mentioned as summarized by the WHO. According to the WHO definition, DDD is the average dose of the drug which is used for its main indication in adults and the PDD is the average dose which is prescribed according to the number of prescriptions and it gives the amount of drug that is actually prescribed. We calculated $\mathrm{PDD}=$ total dose divided by the number of days. Then, the PDD/DDD ratio was calculated to know the adequacy of dosing. Descriptive tables were generated and appropriate proportions were calculated.

\section{RESULTS}

During the study period, out of 1280 prescriptions, a total of 526 prescriptions had hypolipidaemic drugs. There was nearly equal gender distribution of the patients who received hypolipidaemic drugs. The number of prescriptions with hypolipidaemic drug with lipid profile has been shown in [Table 1]. The distribution of disease pattern with lipid profile is shown in [Table 2].

The hypolipidaemic drugs which were prescribed for different disease conditions belonged mainly to single agents (statins, fibric acid derivatives) or to fixed dose combinations (statin with aspirin, statin with aspirin and clopidogrel etc.,). The prescribing patterns of these drugs for different diseases have been depicted in [Table 3]. There was not even a single drug which was prescribed by its generic name. The ATC coding, DDDs of the prescribed hypolipidaemic drugs and PDD/DDD ratios were determined for each drug. Atorvastatin was prescribed as underdosed $(\mathrm{PDD} / \mathrm{DDD}<1)$ and rosuvastatin was prescribed as overdosed (PDD/DDD is $>1$ ), as has been shown in [Table 4].

Table 1: Number of prescriptions containing hypolipidaemic drug with lipid profile.

\begin{tabular}{|lccccccc|}
\hline Age & $\begin{array}{l}\text { Total no. of } \\
\text { prescriptions }\end{array}$ & $\begin{array}{l}\text { No. of prescriptions with } \\
\text { hypolipidaemic drugs }\end{array}$ & $\begin{array}{l}\text { Patients with normal } \\
\text { lipid profile }\end{array}$ & \multicolumn{3}{l|}{$\begin{array}{l}\text { Patients with abnormal } \\
\text { lipid profile }\end{array}$} \\
\hline $\mathbf{2 0 - 3 0}$ & 7 & $\mathbf{N}$ & $\mathbf{\%}$ & $\mathbf{N}$ & $\mathbf{\%}$ & $\mathbf{N}$ & $\mathbf{\%}$ \\
\hline $\mathbf{3 1 - 4 0}$ & 21 & 6 & - & 7 & - & - & \\
\hline $\mathbf{4 1 - 5 0}$ & 81 & 58 & 11.14 & 3 & 0.57 & 3 & 0.57 \\
\hline $\mathbf{5 1 - 6 0}$ & 128 & 112 & 21.29 & 34 & 6.46 & 24 & 4.56 \\
\hline $\mathbf{6 1 - 7 0}$ & 163 & 160 & 30.41 & 9 & 5.70 & 82 & 15.58 \\
\hline$>\mathbf{7 1}$ & 190 & 190 & 36.12 & 2 & 0.38 & 188 & 35.74 \\
\hline Total & 590 & 526 & & 85 & 14.82 & 448 & 85.15 \\
\hline
\end{tabular}

Table 2: Distribution of disease pattern with lipid profile.

\begin{tabular}{|c|c|c|c|c|c|c|}
\hline \multirow{2}{*}{ Diseases } & \multicolumn{2}{|c|}{$\begin{array}{l}\text { No. of prescriptions with } \\
\text { hypolipidaemic drug }\end{array}$} & \multicolumn{2}{|c|}{$\begin{array}{l}\text { Normal lipid } \\
\text { profile }\end{array}$} & \multicolumn{2}{|c|}{$\begin{array}{l}\text { Abnormal lipid } \\
\text { profile }\end{array}$} \\
\hline & $\mathbf{N}$ & $\%$ & $\mathbf{N}$ & $\%$ & $\mathbf{N}$ & $\%$ \\
\hline CAD+diabetes & 124 & 23.57 & 37 & 7.03 & 87 & 16.53 \\
\hline CAD+diabetes+hypertension & 188 & 35.74 & 63 & 11.97 & 125 & 23.76 \\
\hline CAD+hypertension & 116 & 22.05 & 39 & 7.41 & 77 & 14.63 \\
\hline CAD & 98 & 18.63 & 44 & 8.36 & 54 & 10.26 \\
\hline Total & 526 & & 183 & 34.77 & 343 & 65.18 \\
\hline
\end{tabular}

CAD: Coronary artery diseases. 
Table 3: Prescribing pattern of different drugs for different diseases.

\begin{tabular}{|c|c|c|c|c|c|c|c|c|c|c|c|c|}
\hline \multirow[t]{2}{*}{ Drugs } & \multicolumn{2}{|c|}{$\begin{array}{l}\text { CAD+ } \\
\text { diabetes }\end{array}$} & \multicolumn{2}{|c|}{$\begin{array}{l}\text { CAD+ } \\
\text { diabetes+ } \\
\text { hypertension }\end{array}$} & \multicolumn{2}{|c|}{$\begin{array}{l}\text { CAD + } \\
\text { hypertension }\end{array}$} & \multicolumn{2}{|c|}{ CAD } & \multicolumn{2}{|c|}{ Others } & \multicolumn{2}{|c|}{ Total } \\
\hline & $\mathbf{N}$ & $\%$ & $\mathbf{N}$ & $\%$ & $\mathbf{N}$ & $\%$ & $\mathbf{N}$ & $\%$ & $\mathbf{N}$ & $\%$ & $\mathbf{N}$ & $\%$ \\
\hline Atorvastatin & 44 & 26.99 & 36 & 22.08 & 49 & 30.06 & 22 & 13.49 & 12 & 7.36 & 163 & 30.98 \\
\hline Rosuvastatin & 15 & 24.19 & 18 & 29.03 & 13 & 20.96 & 10 & 16.12 & 6 & 9.67 & 62 & 11.78 \\
\hline Fenofibrate & 1 & 50 & 0 & & 1 & 50 & - & & - & & 2 & 0.38 \\
\hline Atorvastatin+aspirin & 17 & 26.15 & 20 & 30.76 & 12 & 18.46 & 9 & 13.84 & 7 & 10.76 & 65 & 12.35 \\
\hline $\begin{array}{l}\text { Atorvastatin+aspirin+ } \\
\text { clopidogrel }\end{array}$ & 12 & 13.04 & 34 & 36.95 & 11 & 11.95 & 27 & 29.34 & 8 & 8.69 & 92 & 17.49 \\
\hline Rosuvastatin+aspirin & 16 & 25 & 18 & 28.12 & 13 & 20.31 & 9 & 14.06 & 8 & 12.5 & 64 & 12.16 \\
\hline $\begin{array}{l}\text { Rosuvastatin+aspirin } \\
\text { +clopidogrel }\end{array}$ & 18 & 23.07 & 26 & 33.33 & 15 & 19.23 & 10 & 12.82 & 9 & 11.53 & 78 & 14.82 \\
\hline
\end{tabular}

Table 4: ATC coding with PDD:DDD ratio.

\begin{tabular}{|lllll|}
\hline Drugs & ATC code & PDD & DDD & PDD/DDD \\
\hline Atorvastatin & C10AA05 & 17.65 & 20 & 0.88 \\
\hline Rosuvastatin & C10AA07 & 13.22 & 10 & 1.32 \\
\hline Fenofibrate & C10AB05 & 160 & 160 & 1 \\
\hline Atorvastatin+aspirin & C10BX & 20 & 20 & 1 \\
\hline Atorvastatin+aspirin+clopidogrel & C10BX & 1UD & 1UD & 1 \\
\hline Rosuvastatin+aspirin & C10BX & 1UD & 1UD & 1 \\
\hline Rosuvatatin+aspirin+clopidogrel & C10BX & 1UD & 1UD & 1 \\
\hline
\end{tabular}

\section{DISCUSSION}

Many studies have been carried out on the drug prescribing patterns of hypolipidaemic drugs such as statins in many developed and developing countries. ${ }^{4}$ As with the increasing trends, India is becoming the global centre for various diseases like diabetes and cardiovascular diseases. So, there is a necessity to look upon the risk factors as well as to develop appropriate treatment guidelines for these diseases. The main objective of the present study was to evaluate the drug prescribing patterns of hypolipidaemic drugs which were prescribed for various diseases in the department of cardiology. On observation, it was revealed that the prescriptions containing hypolipidaemic drugs were higher in men than with women. This indicated that there was an increase in prevalence of dyslipidaemia among Indian men. Previous studies have suggested that the prevalence of CHD in Indian was high in men as that seen in women. ${ }^{5}$ Our study showed higher number of patients of dyslipidemia as the age advances. Geldsetzer et al, observed that the prevalence of diabetes, hypertension and other dyslipidaemia conditions were higher in middle age and old age. ${ }^{6}$ Also, it was found that hypolipidaemic drugs were prescribed mostly to dyslipidaemia patients as well as to normal lipid profile patients. Diabetes with other co morbid conditions were the majority of patients who were prescribed hypolipidaemic drugs. This may be due to the fact that these prescriptions were assessed at a tertiary care hospital, which was a referral centre for a large population. The results also revealed that hypolipidaemic drugs were prescribed for these disease conditions, irrespective of the lipid profile statuses of the some patients which may be the strategy for primary as well as secondary preventions of cardiovascular complications which were as par with the latest guideline on the management of blood cholesterol by ACC. ${ }^{3}$ Also, according to the data obtained, statins were the most commonly prescribed hypolipidaemic drugs. Most prescriptions had single hypolipidaemic drug. The choice of the statin as monotherapy or as a combination drug with aspirin, clopidogrel or fibrates was based on the disease process. Among the statins, atorvastatin was most commonly used hypolipidaemic drug and was preferred widely as a single hypolipidaemic agent. The combination of atorvastatin with aspirin was prescribed mainly for coronary artery disease with co morbid diseased patients. The other fixed dose combinations of atorvastatin were prescribed for cardiovascular diseases associated with diabetes and hypertension. Several studies have shown that statins were the first line lipid lowering drugs used for primary as well as secondary preventions of coronary artery diseases. ${ }^{7}$ Prescription writing is according to rational prescription writing given by WHO ${ }^{8}$ Not even a single drug was prescribed by its generic name, which may be due to lack of awareness or absence of safe prescribing guidelines. ${ }^{9}$ The ATC classification of drugs is done as per their chemical, pharmacological and therapeutic properties as mentioned in the WHO. ${ }^{10}$ DDD is defined by the WHO collaborating centre for drug statistics and methodology as the assumed average maintenance adult dose per day for its main indications. It is a unit of measurement and 
does not correspond to PDD. PDD is defined as the average dose prescribed according to a representative sample of prescriptions. The ratio of PDD to DDD gives an idea about the adequacy of dosing. A ratio of less than 1 indicates underdosing, whereas a ratio of more than 1 indicates overdosing. In this study, it was found that atorvastatin was prescribed as underdosed. Although the use of statins has increased many folds over the past, they are still underused. The reason for this underuse has been poorly explained. In clinical practice, statins are prescribed at lower doses so that it can be titrated upwards to higher doses, which has a reduced risk of cardiovascular effects. The other statin i.e., rosuvastatin was overdosed. All other hypolipidaemic drugs which had a PDD to DDD ratio which was equal to one reflected the adequacy of dosing.

\section{CONCLUSION}

As the age advances the incidence of cardiovascular diseases increases and so the prescription of statin increases accordingly due to the increased risk of atherosclerosis which leads to many complications. From the above results it is known that atorvastatin is the most common drug prescribed and atorvastatin with aspirin and clopidogrel as the most common combination drug. Generic drugs were not used even in single prescription, so, the prescribing physicians should be informed about the importance of prescribing generic drugs and also about adequacy of dosing.

Funding: No funding sources

Conflict of interest: None declared

Ethical approval: The study was approved by the Institutional Ethics Committee

\section{REFERENCES}

1. Pencina MJ, Navar-Boggan AM, D’Agostino RB, Williams K, Neely B, Sniderman AD, et al. Application of new cholesterol guidelines to a population-based sample. $\mathrm{N}$ Engl $\mathrm{J}$ Med. 2014;370:1422-31.

2. Goff DC, Lloyd-Jones DM, Bennett G, Coady S, D’Agostino RB, Gibbons R, et al. 2013 ACC/AHA Guideline on the Assessment of Cardiovascular Risk: a report of the American College of Cardiology/American Heart Association Task Force on Practice Guidelines. Circulation. 2014;129:S4973.

3. 2018 Guideline on the Management of Blood Cholesterol: A Report of the American College of Cardiology/American Heart Association Task Force on Clinical Practice Guidelines. J AM Coll Cardiol. 2018; 10.

4. Pankaj G, Sharma G, Baljinderpal S, Singh J, Singh J, Randhawa GK, et al. Prospective, noninterventional, uncontrolled, open chart, pharmacoepidemiologic study of prescribing patterns for lipidlowering drugs at a tertiary care teaching hospital in North India. Clinical Therapeutics. 2002;24(12):2064-76.

5. Gupta R, Mohan I, Narula J. Trends in coronary heart disease epidemiology in India. Annals of Global Health. 2016;82(2):307-15.

6. Geldsetzer P, Manne-Goehler J, Theilmann M, Davies JI, Awasthi A, Vollmer S, et al. Diabetes and Hypertension in India: A Nationally Representative Study of 1.3 Million Adults. JAMA Internal Med. 2018;178(3):363-72.

7. Lim SP. Role of statins in Coronary artery Disease. Chonnam Med J. 2013;49(1):1-6.

8. Iain LO. Principles of prescription order writing and patient compliance. In: Brunton L, Chabner B, Knollman B. Goodman and Gilman's The Pharmacological basis of Therapeutics. 12th ed. USA: McGraw Hill; 2011: 1879.

9. Safe prescribing. Available at: http://www.gmcuk. org/guidance/ethical_guidance/14316.asp. Accessed on 11 September 2019.

10. ATC Classification. Available at: https://www.who. int/medicines/regulation/medicines-safety/toolkit_atc /en/. Accessed on 11 September 2019.

Cite this article as: Gari M, Bansal M. Prescription analysis of hypolipidaemic agents in the department of cardiology in a tertiary care hospital. Int J Basic Clin Pharmacol 2019;8:2557-60. 